\title{
Role of the Cortisol Hormone, Interleukin-5 Level, and Asthma Control Ability in Atopy Persistent Asthma
}

\author{
1st Rahmaya Nova \\ Handayani \\ Anesthesiology Study \\ Program of Universitas \\ Harapan Bangsa, \\ Purwokerto, Indonesia, \\ mayanova2005@gmail.c \\ 4th Iris Rengganis \\ Department of Internal \\ Medicine, Faculty of \\ Medicine Universitas \\ Indonesia; Dr. Cipto \\ Mangunkusumo Hospital, \\ Jakarta, Indonesia,
}

\author{
$2^{\text {nd }}$ Faisal Yunus \\ Department of \\ Pulmonology and \\ Respiratory, Faculty of \\ Medicine, Universitas \\ Indonesia, Persahabatan
}

\author{
3rd Ermita Isfandiary \\ Ibrahim Ilyas \\ Department of Medical \\ Physiology, Faculty of \\ Medicine Universitas \\ Indonesia, Jakarta, \\ Indonesia,
}

Introduction: Asthma is a chronic inflammatory disorder of the respiratory tract. The interaction among several hormones and mediators causes asthma symptoms. This study aimed to identify a correlation between the cortisol hormone, interleukin5 level, and asthma control in asthma atopy persistent. Materials and Methods: 39 atopic participants of asthma group and 26 participants of non-asthma group were taken from the medical record in Prof. Dr. Margono Soekarjo Purwokerto hospital Central Java Indonesia. Peripheral blood mononuclear cells were isolated 72 hours with house dust mite allergens stimulation. Plasma levels of cortisol hormone and interleukin-5 were measured using an enzyme-linked immunosorbent assay kit. The ability to control symptoms was assessed using the Asthma Control Questionnaire. Results and Conclusions: Based on statistical analysis the results showed that there were differences between cortisol levels of asthma and nonasthmatic groups $(p=0.001)$, there was correlation cortisol hormone with interleukin-5 stimulation of house dust mites allergens $(p=0.04)$, there was no correlation interleukin-5 stimulation of house dust mite with asthma control ability $(p=0.42)$, and there was no correlation between the hormone cortisol and asthma control ability $(p=0.38)$. Therefore, cortisol hormone healthy subject was higher than asthma subject and thus there was correlation of cortisol hormone and interleukin-5 house dust mite allergens, and there were no correlation interleukin-5 house dust mite allergens and cortisol hormone with asthma control ability.
Keywords: atopy persistent asthma, asthma control ability, cortisol hormone, interleukin- 5

\section{INTRODUCTION}

Asthma is a chronic inflammatory disorder of the respiratory tract. Asthma can disrupt the activity, productivity, and quality of life of patients. ${ }^{[1]}$ According to the World Health Organization, the incidence of asthma increases by 200.000 each year worldwide. ${ }^{[2]}$ In addition to bronchial hyperactivity, asthma pathogenesis involves the secretion of the glucocorticoid hormone cortisol. It is produced in humans by the zona fasciculate of the adrenal cortex within the adrenal gland. Cortisol can prevent the release of substances in the body that cause inflammation. Cortisol can increase the response of $\beta$-adrenergic receptors in bronchial smooth muscles. Cortisol can reduce airway hyperresponsiveness in asthma patients because it reduces the number of circulating eosinophils, and inhibits the production and secretion of cytokines in the respiratory tract. These actions cause the release of epinephrine and norepinephrine, which result in dilatation of bronchial smooth muscles. ${ }^{[3,4]}$ The pathophysiology of allergic diseases (including asthma) involves inflammation. Respiratory inflammation involves the interaction of several cell types and mediators that cause asthma symptoms. Interleukin (IL)-5 inhibits the release of cortisol and lipid mediators which can damage cells and cause bronchial hyperresponsiveness and mucus hypersecretion. ${ }^{[5,6]}$ This 
study aimed to identify the role of the cortisol hormone and interleukin 5 on stimulation dust mite in persistent asthma.

\section{METHODS}

\section{Subject :}

The data was taken from medical record Prof.dr.Margono Soekarjo Purwokerto Central Java Indonesia. We divided into 2 groups: asthma groups (39 participants) and nonasthma groups (26 participants).

Inclusion criteria in Asthma Group: people aged 19-67 years; no worm eggs in feces; a positive skin prick test (SPT) for allergens from the house dust mites Dermatophagoides pteronyssinus, Dermatophagoides farinae, or Blomia tropicalis. Non-Asthma Group: no history of asthma, no family history of asthma, negative skin prick test results

Exclusion criteria in asthma group

Exclusion criteria: people with an acute lung infection (acute respiratory infection, bronchopneumonia, lung abscess, and empyema) or chronic pulmonary infection (tuberculosis or bronchiectasis); obese (based on the body mass index).

\section{Biochemical measurements}

A standard of cortisol (catalogue number: KGE008B) was purchased from R\&D Systems (Minneapolis, MN, USA). The hormone cortisol was taken from the blood plasma at 79 am and interleukin-5 was taken from peripheral blood mononuclear cells that were isolated using standard methods in 72 hours incubation with stimulation house dust mites Dermatophagoides pteronyssinus (Der p) and control negative using Roswell Park Memorial Institute 1640 (RPMI) medium and both were taken from supernatants. Plasma levels of cortisol and interleukin-5 (D5000B; R\&D Systems) were measured using an enzyme-linked immunosorbent assay kit (ELISA).

Asthma control questionnaire: The ability to control symptoms was assessed using the asthma control questionnaire (ACQ) (which can be used only in people aged $\geq 17$ years). Study participants were interviewed about their asthma symptoms, their response to these symptoms, and the use of bronchodilators. The asthma control questionnaire comprised seven questions based on five main symptoms. It had seven points of scale $(0=$ no deterioration/totally controlled asthma; $6=$ severe deterioration/not able to control asthma). All questions in the asthma control questionnaire carried the same weight. All questions had to be completed, but sometimes the Forced Volume in 1 Second (FEV1) measurement was not made. If the mean score using six questions was $>1.5$, then asthma could be controlled well; if it was $<0.75$, then it could not be controlled well.[7]

Statistical analyses: Statistical analyses were undertaken using the Mann-Whitney test to compare cortisol hormone asthma groups and non-asthma groups; the Wilcoxon test was used to analyse interleukin-5 of the negative control and Interleukin-5 house dust mites allergens stimulation; and Pearson analyses were used to find out the correlation among variables. SPPS v22 (IBM, Armonk, NY, USA) was applied to analyse the data. It showed $\mathrm{p}<0.05$ and it was considered as significant.

\section{RESUlTS AND DisCUSSIONS}

Cortisol hormone examination was taken from blood plasma at $07.00-09.00 \mathrm{am}$. It was taken from plasma because after separation or centrifugation it could last longer than serum. Plasma also had recovery power (average percentage) with higher linearity than serum (97: 95; range (\%): 94 - 103 in plasma while serum 89: 100. Cortisol hormone measurement using ELISA with the brand: DRG International, Inc., USA (Cat.Num: EIA 1887). Cortisol hormone levels were higher in non-asthmatic subjects than asthma subjects (Figure 1).

The cortisol hormone level in the measurement of serum or plasma samples at 08.00-10.00 am was $50 \mathrm{ng} / \mathrm{mL}-230 \mathrm{ng} /$ $\mathrm{mL}$ (138-635 nmol / L).

Figure 2 describes that Interleukin-5 levels in the stimulation of house dust mites Derp were significantly higher than Interleukin-5 levels in negative controls.

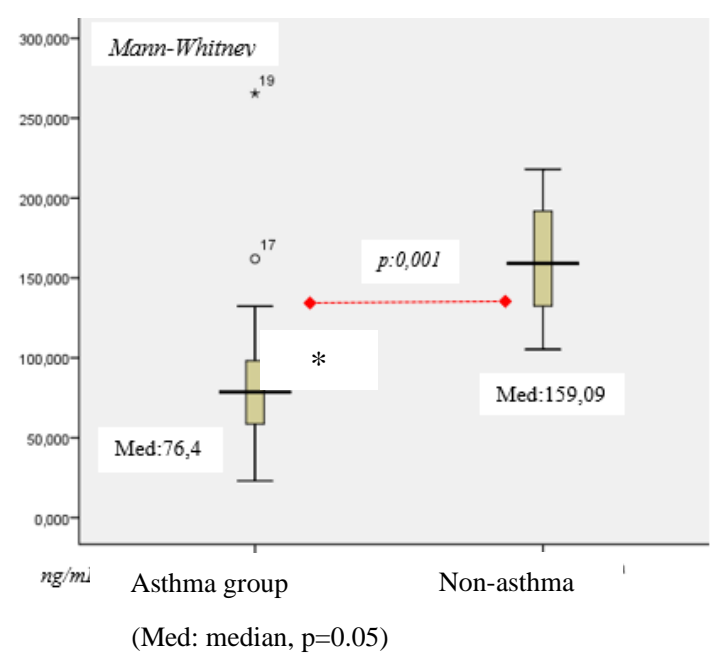

Fig 1. The comparison of cortisol hormone in the asthma group and non-asthma group 
Based on Figure 2, it can be seen that the stimulation of Der $\mathrm{p}$ house dust mite allergens increased significantly than interleukin-5 levels in negative controls with a value of $\mathrm{p}=$ $0.000(\alpha=0.05)$. Stimulation of home dust mites Der $p$ given to Peripheral Blood Mononuclear Cell (PBMC) isolation showed that the body responded repeatedly exposure to the allergen

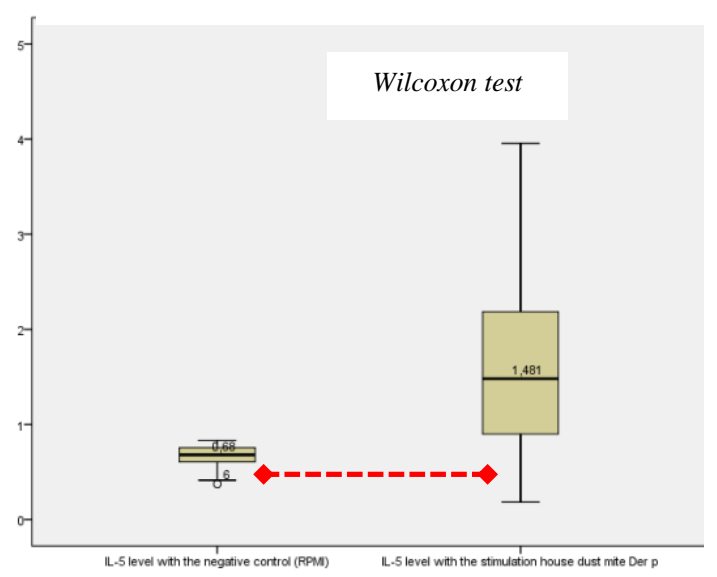

Fig 2. The comparison of IL-5 level with the negative control and stimulation house dust mites Der $\mathrm{p}$ in the asthma group

Finally, to determine the correlation between cortisol hormone and interleukin-5 house dust mites Dermatophagoides pteronyssinus stimulation and asthma control ability, we performed the Pearson test. As shown in table 1, the levels of cortisol hormone were correlated with the circulating interleukin-5 house dust mites Der $p$ stimulation levels $(p=0.04)$. The levels of cortisol hormone were not correlated with the asthma control ability $(\mathrm{p}=$ 0.38). The levels of the circulating IL5 house dust mites Der $\mathrm{p}$ stimulation levels were not correlated with the asthma control ability $(\mathrm{p}=0.42)$.

Table 1. The correlation between the hormone cortisol, interleukin-5 and asthma control ability

\begin{tabular}{|c|c|c|}
\hline & $\begin{array}{c}\text { Asthma } \\
\text { control } \\
\text { ability } \\
\text { (p-value) }\end{array}$ & $\begin{array}{c}\text { Interleukin-5 house dust } \\
\text { mites } \\
\text { Dermatophagoides } \\
\text { pteronyssinus, } \\
\text { stimulation } \\
\text { (p-value) }\end{array}$ \\
\hline $\begin{array}{l}\text { The cortisol } \\
\text { hormone }\end{array}$ & 0.38 & 0.04 \\
\hline $\begin{array}{lrr}\text { IL-5 house } & \text { dust } \\
\text { mites Der } & p \\
\text { stimulation } & \end{array}$ & 0.42 & - \\
\hline
\end{tabular}

The hypothalamic-pituitary-adrenal (HPA) axis is a feedback system between the hypothalamus, pituitary gland, and adrenal gland. The hypothalamus secretes a corticotrophin-releasing hormone (CRH) through the hypothalamic-pituitary-adrenal axis. The corticotropinreleasing hormone stimulates the anterior pituitary gland to release corticotrophin through blood vessels to the adrenal cortex. Then, corticotrophin regulates cortisol production, and cortisol in the body responds to stress.[8] Based on Figure 1, it was found that the hormone cortisol levels in asthma and non-asthma groups had a p-value: 0.001 . According to the Landstra in 2002, there was a decrease in the hormone cortisol level in the asthma group compared to the normal group. This can also be seen in the results of this study which showed the results of significant differences between asthma and non-asthma groups.[9] Cortisol hormone levels were higher in non-asthmatic subjects than asthma subjects, with median values; 76.4 in the asthma group and 159 in the non-asthma gro ${ }^{\cdots *}$

In addition to the role $\mathrm{o} *$ ichial hyperactivity, asthma pathogenesis involves cortisol secreted by the hypothalamicpituitary-adrenal axis. Cortisol has anti-inflammatory activity and suppresses the immune system by following a circadial $\quad(*: p=0.000 ; \alpha=0.05) \quad$ of cortisol are from 7 am to 9 am.[8] P. $\left.{ }^{*}: p=0.000 ; \alpha=0.05\right)$ activates the hypothalamicpituitary-adrenal axis, resulting in the release of cortisol, which has anti-inflammatory effects. However, other regulatory pituitary corticotrophins and hypothalamic hormones (corticotrophin-releasing hormone and vasopressin) of the hypothalamic-pituitary-adrenal axis have systemic immunopotentiating and pro-inflammatory effects. Eosinophils and lymphocytes are believed to be key effector cells of airway-wall inflammation in asthma because they release pro-inflammatory mediators and cytokines.[10] Also, neutrophils may have a role, especially during exacerbations of asth $p g / m L$ viral respiratory infections. Corticosteroids are $\mathrm{knc} . . . . . .$. their potent anti-inflammatory activity in allergic asthma.[11] The hypothalamus specifically in the periventricular nucleus secretes a corticotropin-releasing hormone that binds to the corticotrophin-releasing hormone receptor stimulating the anterior pituitary gland and stimulates pro-opiomelanocortin (POMC) to produce adrenocorticotrophic.

Adrenocorticotropic hormone is then released into the blood vessels to synthesis the hormone cortisol. Enzyme $11 \beta$ Hydroxysteroid-dehydrogenases is an enzyme that functions to convert cortisone to cortisol, so the failure of the formation of this enzyme due to increased Th2 activity can interfere with the formation of cortisone into cortisol which aggravates the appearance of asthma symptoms.

Based on the Wilcoxon test there was 1 participant who experienced a decrease after stimulation of house dust mites allergens and 38 participants experienced an increase (figure 
was an approach to the therapy with anti interleukin 5 and the steroid combination for the patients with persistent asthma. responsible for the maturation and the release of eosinophils in the bone marrow. Following a study of Shiota $e t$ al in 2001, a higher percentage of interleukin-5 producing CD3 $\mathrm{T}$-cell was detected in subjects with atopic and non-atopic asthma.[12] Based on Figure 2, it can be seen that Dermatophagoides pteronyssinus house dust mites allergens stimulation increased significantly than interleukin-5 levels in the negative control with a $p$ value $=0.000(\alpha=0.05)$, this was due to the sensitized/induced research subject which was the first contact to appear when the body produces Immunoglobulin $\mathrm{E}$ antibodies that are specific to the allergy induction stage. Dermatophagoides pteronyssinus house dust mites stimulation given made the body respond to exposure to these allergens repeatedly.[13]

Based on table 1, there was no correlation between the levels of cortisol hormone and interleukin-5 of the negative control. It showed that there was a correlation between cortisol hormone and interleukin--5 levels on stimulation of house dust mites allergens Der p. During an inflammatory reaction, the release of cytokines results in the activation of stress responses. Glucocorticoids and catecholamines are major stress hormones, which can reduce the expression of inflammatory genes that are activated during the inflammation process preventing toxicity and tissue damage. Stress hormones can affect the immune response in several ways. During the inflammatory response, activating stress hormones inhibits T-helper 1 and T-helper 2 or proinflammatory responses.[14]

Asthma control is important for the evaluation of patients and their response to treatment, but the terminology is not standardized. 'Asthma control' refers to the extent to which the manifestations of asthma have been reduced or removed by treatment.[15] Louis and colleagues stated that there was a relationship between airway inflammation and asthma severity.[16] Based on table 1, there was no correlation between the Interleukin -5 (control negative and stimulation house dust mites allergens Der $p$ ) with the ability to control asthma, and no correlation between the cortisol hormone and the ability to control asthma. We assumed that the severity of asthma and inflammation affected how patients controlled their asthma. The limitation of this study was on the level cortisol hormone that could be affected the sex, age, nutritional and psychological status

\section{CONCLUSIONS}

Cortisol hormone in healthy subject was higher than asthma subject. The results showed that: there was correlation cortisol hormone with interleukin-5 house dust mite allergens, there was no correlation cortisol hormone with asthma control ability and there was no correlation interleukin-5 stimulation house dust mites with asthma control ability. The implication of this study for the future

\section{Acknowledgments}

Thank you to the Ministry of Research and Technology who has given this research grant.

\section{Financial support and sponsorship}

This study was funded by the Ministry of Research and Technology DIKTI 2019 (Basic Research Award 2019)

\section{Conflict of Interest}

No Conflict Interest

\section{Ethical Clearance}

The study received ethical approval from the Institutional Review Board of the Faculty of Medicine Universitas Indonesia (Ethical Clearance No. 998/UN. F1/ETIK/2017)

\section{REFERENCES}

[1] ginasthma.org [Internet]. Bethesda: Global Initiative for Asthma; c2016 [cited 2017 Mar 5]. Available from: http://www.ginasthma.org

[2] Departemen Penyehatan Lingkungan. Pedoman Pengendalian Asma. Jakarta: Departemen Kesehatan Kesehatan RI. Direktorat Jenderal Pengendalian Penyakit dan RI; 2013.

[3] Barrett KE, Boitano S, Bahman SM. Brook HL. Ganong's Review of Medical Physiology. 28th ed. New York: Lange Mc Graw Hill; 2010.

[4] Tortora GJ, Derricson BH. Principles of Anatomy and Physiology.12thed. New York: John Wiley and Sons; 2009.

[5] Olsen PC, Kitoko JZ, Ferreira TP, de-Azevedo CT, Arantes AC, Martins MA. Glucocorticoids decrease Treg cell numbers in lungs of allergic mice. Eur $\mathbf{J}$ Pharmacol. Eur J Pharmacol. 2015 Jan 15;747:52-8.

[6] Brode S, Farahi N, Cowburn AS, Juss JK, Condliffe AM, Chilvers ER. Interleukin-5 inhibits glucocorticoid-mediated apoptosis in human eosinophils. Thorax. 2010 Dec;65(12):1116-7.

[7]Juniper EF. Asthma Control Questionnaire. Background, Administration And Analysis. QOL Technologies Ltd. Canada; 2012.

[8] Morey JN, Boggero IA, Scott AB, Segerstrom SC. Current directions in stress and human immune function. Curr Opin Psychol. 2015 Oct 1; 5:13-17. WM. Role of serum cortisol levels in children with asthma. Am J Respir Crit Care Med. 2002 Mar;165(5):708-12.
[9] Landstra AM, Postma DS, Boezen HM, van Aalderen 
[10] Walford HH, Doherty TA. Diagnosis and management of eosinophilic asthma: a US perspective. J Asthma Allergy. 2014 Apr 11; 7:53-65.

[11] Barnes PJ. Pathophysiology of asthma. Eur Respir Mon. 2003;23:84-113.

[12] Shiota Y, Arikita H, Horita N, Hiyama J, Ono T, Yamakido M. Intracellular IL-5 and T-lymphocyte subsets in atopic and atopic bronchial asthma. J Allergy Clin Immunol. 2002.

[13] Galli SJ and Tsai M. IgE and mast cells in allergic disease. Nat Med. 2013 May 4. 18(5):693-704.
[14] Elenkov IJ. Glucocorticoids and the Th1/Th2 balance. Ann NY Acad Sci 2004 Jun;1024:138-46.

[15] Taylor DR, Bateman ED, Boulet LP, Boushey HA, Busse WW, Casale TB, et al. A new perspective on concepts of asthma severity and control. J Eur Resp. 2008 Sep;32(3):545-54.

[16] Louis R, Lau LCK, Bron AO, Roldaan AC, Radermecker M, Djukanovic R. The relationship between airways inflammation and asthma severity. Am J Respir Crit Care Med. 2000;161:9-16. 